\title{
Efetividade da cobrança pelo uso da água e implicações na configuração da agricultura irrigada em Cristalina/GO
}

O presente estudo versa sobre a efetividade da instituição da cobrança pelo uso da água na Bacia Hidrográfica do Paranaíba. Por meio do método programação linear foram elaborados cenários alternativos à configuração atual de uso do solo pela agricultura irrigada, decorrentes dos diferentes valores de cobrança a serem instituídos gradualmente, a partir de 2017, modelando uma função objetivo como resultante do máximo retorno financeiro promovido no município pelo conjunto de culturas irrigadas, dadas as restrições de disponibilidade hídrica e de área agrícola. Os resultados apontam que devido ao fato de que os valores de cobrança instituídos não impactam significativamente a receita total do produtor irrigante não haveria mudanças na configuração da agricultura irrigada, todavia, os valores arrecadados se apresentam como fonte de investimentos para recuperação/conservação dos corpos hídricos na própria bacia.

Palavras-chave: Instrumentos econômicos; Gestão pública; Recursos hídricos.

\section{Effectiveness of the collection of water use and implications in the configuration of irrigated agriculture in Crystaline/GO}

The present study is about the effectiveness of the institution of a fee, to be charged by the water use in the Paranaíba River Basin. Through the linear programming method, alternative scenarios were elaborated to the current configuration of land use by irrigated agriculture, resulting from the different collection values to be instituted gradually, starting in 2017 , modeling the function goal resulting of the maximum financial return promoted in the municipality by the set of irrigated crops, given the restrictions on water availability and agricultural area. The results indicate that, due the fact that the collected values do not significantly impact the total income of the irrigating producer there would be no changes in the configuration of irrigated agriculture, however, the amounts collected are presented as a source of investments for the recovery / conservation of water bodies in the basin itself.

Keywords: Economic instruments; Public management; Water resources.

Topic: Planejamento, Gestão e Políticas Públicas Ambientais

Reviewed anonymously in the process of blind peer.
Received: 14/12/2017

Approved: 24/01/2018

Maria Gáucia Dourado Furquim (iD

Instituto Federal de Educação, Ciência e Tecnologia Goiano, Brasil http://orcid.org/0000-0001-7823-9546

maria.furquim@ifgoiano.edu.br

Klaus de Oliveira Abdala (iD

Universidade Federal de Goiás, Brasil

http://lattes.cnpq.br/8041644148923970

http://orcid.org/0000-0002-6466-9905

agroklaus@gmail.com

Referencing this:

FURQUIM, M. G. D.; ABDALA, K. O.. Efetividade da cobrança pelo uso da água e implicações na configuração da agricultura irrigada em Cristalina/GO. Revista Ibero Americana de Ciências Ambientais, v.9, n.2, p.277-290, 2018. DOI: http://doi.org/10.6008/CBPC2179$\underline{6858.2018 .002 .0023}$ 


\section{INTRODUÇÃO}

Correspondendo a $42 \%$ da produção agrícola de alimentos de consumo humano direto no mundo e ocupando aproximadamente $18 \%$ de área agricultada, a agricultura irrigada é apontada como solução de equilíbrio para a demanda mundial por alimentos (CHRISTOFIDIS, 2006). Atualmente, do total de 1,5 bilhões de hectares de solo destinados à produção agrícola no planeta, cerca de 270 milhões possuem algum sistema de irrigação e, desse total, $3 \%$ se encontra no Brasil, o que corresponde a aproximadamente 8.000 .000 de hectares, além disso, o país detém 13\% do potencial de incremento mundial em área irrigada (ANA, 2014).

O estado de Goiás, com aproximadamente 300.000 hectares de sua área agrícola irrigada, corresponde a $4 \%$ da área nacional. Dentre os municípios goianos que se destacam pelo crescimento e pela expansão no uso de tecnologias de irrigação no exercício das atividades agrícolas, está o município de Cristalina, que detém 25\% da área do estado de Goiás (ANA, 2014).

Localizado na mesorregião do leste goiano, entorno de Brasília, Distrito Federal, foi criado em 1916, tendo como base econômica a extração e comercialização de cristal de rocha e atividades pastoris de subsistência. Entretanto, a partir da década de 1970 estas atividades foram sendo gradualmente substituídas por uma diversidade de culturas destinadas a atender novos mercados. Atualmente, o município vem se consolidando como polo do agronegócio brasileiro, tendo como principal fonte geradora de emprego, renda e riqueza o setor agropecuário.

Devido a concentração de grandes empreendimentos agrícolas irrigados, que se destacam nacionalmente, Cristalina é hoje o município com maior área irrigada por pivô central da América Latina (FURQUIM et al., 2017) e 8o município brasileiro em termos de valor bruto adicionado pela agropecuária (IBGE, 2010). Todavia, a disponibilidade hídrica para o setor irrigante e demais setores da economia, mostrase incipiente no município (FURQUIM et al., 2017), demandando maior efetividade das políticas de gestão dos recursos hídricos.

Conforme Deliberação no 61, de 10 de março de 2016, estabelecida pelo CBH Paranaíba (2016), que dispõe, em seu caput, "sobre mecanismos e valores de cobrança pelo uso de recursos hídricos de domínio da União", a cobrança pelo uso da água foi instituída como política de gestão dos recursos hídricos na bacia hidrográfica interestadual do Rio Paranaíba, composta pelos corpos hídricos que abastecem o município de Cristalina.

Instrumentos de mercado, tais como a cobrança pelo uso da água, são utilizados como políticas ambientais com o objetivo de responsabilizar o usuário do recurso pelas externalidades de uso do mesmo uma vez que, ao internalizar custos sociais ao setor privado, estimula o uso mais eficiente do recurso, alterando a percepção de custos no setor e induzindo alterações na configuração produtiva (THOMAS et al., 2010), porém, é possível que a alteração na configuração produtiva afete, por efeito linkcage, toda a sócio economia da região (RIBEIRO et al., 2013). Diante do contexto apresentado este trabalho analisa a efetividade dessa política ambiental no uso eficiente do recurso hídrico e na socioeconomia do município de Cristalina. 


\section{REVISÃO TEÓRICA}

\section{Princípios econômicos do uso dos recursos hídricos}

Os recursos naturais do planeta são fruto de funções ecossistêmicas decorrentes dos ciclos naturais da terra. A dinâmica de recomposição desses recursos estabelece os critérios para classificá-los como recursos renováveis e não renováveis. A água, assim como a fauna e a flora, são elementos considerados, intuitivamente, como recursos naturais renováveis, pois seus ciclos de reconstituição são compatíveis com a percepção de tempo de vida pelo homem. Todavia, tais recursos podem se tornar escassos quando seu fluxo de regeneração não consegue suprir a demanda da população, o que constitui um problema de economia dos recursos naturais. Além disso, especificamente no caso da água, a sua escassez pode, ainda, estar relacionada ao nível de qualidade requerida para determinados fins, e, nesse sentido, seria um problema de economia da poluição.

Apesar de a água ter sido considerada recurso originalmente livre, que pôde ser apropriada sem custo de oportunidade por qualquer usuário, ao longo da história das sociedades esse recurso foi se tornando escasso e se constituindo em bem econômico. Nessa perspectiva, considerando a água como recurso econômico de produção, a sua alocação eficiente deveria ser estabelecida pelo funcionamento do próprio mercado, o qual resolveria os problemas de escassez ou excesso destes recursos em um mercado de fatores.

O mercado opera como regulador das atividades de produção, no qual oferta e demanda são regulados via preços e quantidades, revelando preferências, tendências e atitudes de produtores e consumidores. O meio ambiente interage com o homem e com suas atividades econômicas via mercado ao fornecer fatores de produção utilizados pelas empresas e organizações em seus processos produtivos. Entretanto, essa relação de produção e de consumo pode acarretar impactos negativos para o homem e meio ambiente, caracterizando a ineficiência do mercado no uso do recurso.

Essa ineficiência do mercado é definida na teoria econômica como falhas de mercado, ou seja, quando os mecanismos de mercado, com livre funcionamento (sem a intervenção do Estado como órgão regulador) gera resultados econômicos indesejáveis socialmente. Tais falhas são decorrentes de concorrência imperfeita, informações assimétricas, bens públicos e externalidades (MOTA, 2004).

A concorrência imperfeita é caracterizada a partir da identificação de estruturas de mercado na forma de monopólios e oligopólios, que utilizam recursos de poder (PAULILLO, 2000) e distorcem os preços que tornariam mercados eficientes reguladores de alocação dos recursos. Por sua vez, informações assimétricas se referem a informações incompletas, ou parciais, disponíveis aos agentes econômicos em diferentes níveis, o que ocasiona ineficiência, uma vez que a falta de equidade de informações conduz à adoção de comportamentos oportunistas, não equitativos na distribuição dos produtos.

Para o mercado de fatores ou serviços ambientais, essas imperfeições acentuam a degradação do capital natural no exercício das atividades produtivas, vez que recursos de poder e informações imperfeitas a respeito do valor dos fatores ambientais conduzem os agentes a ações oportunistas, uma vez que utilizam 
vantagens espúrias para a produção de bens, diminuindo os custos de produção e elevando a produção a um nível alocativamente ineficiente do recurso hídrico (RASÇAO, 2007).

Por sua vez, conforme elucida Mota (2004) “[...] o fenômeno, denominado de externalidade, referese ao efeito originário do processo produtivo que é imputado a terceiros, gerando bem-estar econômico para alguns e prejuízos para outros", ou seja, há ineficiência do mercado em internalizar, na forma de custos, os efeitos sociais, econômicos e ambientais decorrentes da produção ou consumo de um produto ou serviço. No caso dos recursos hídricos, o consumo do mesmo por determinados agentes torna sua disponibilidade reduzida para os demais, caso não seja internalizado ao agente consumidor deste recurso, os custos de oportunidade de uso dos demais agentes.

A distinção econômica entre um bem público e um bem privado fundamenta-se no fato de que, quando considerado público, a apropriação ou o consumo do bem não diminui a utilidade dos demais indivíduos, além disso, não é possível restringir o acesso ou o consumo deste bem, logo os bens públicos são disponíveis e acessíveis a todos.

Neste sentido, a classificação dos recursos hídricos torna-se ainda mais complexa, pois, embora sejam considerados bens públicos, podem apresentar-se com alguma das características de um bem privado, ou seja, ser não excludente, mas rival, situação na qual o acesso é difícil de restringir, contudo o consumo de uns limita a capacidade de consumo de outrem. Nesta condição os recursos hídricos assumem característica de 'bens comuns' e, segundo a teoria ${ }^{1}$, conduz à escassez do recurso.

Ainda, esses recursos podem ser excludentes e não rivais, caracterizando-os como bens coletivos, para os quais o acesso pode ser limitado, todavia, o consumo de um indivíduo não reduz a possibilidade de consumo de outro, situação que tem como consequência a geração de conflitos entre os usuários e os excluídos (HENRIQUES et al., 2006).

Como pode ser observado, a forma sob a qual a água é disponibilizada ao usuário determinará os problemas decorrentes uma vez que, segundo esta forma, o recurso hídrico poderá se caracterizar em qualquer das situações anteriormente descritas. No caso da irrigação em Cristalina, a regulamentação via portaria de outorga concedida a um irrigante, associada à fiscalização ineficiente, evidenciada pelo uso da água para irrigação sem outorga, ${ }^{2}$ reduz a disponibilidade de consumo dos demais usuários, dada a limitada quantidade de água na bacia, acentuando ainda mais o problema de escassez física do recurso na região. Essa forma de disponibilização dos recursos hídricos na região caracteriza a água como um bem comum. Por outro lado, ao estabelecer um pagamento pelo consumo da água ao setor agrícola, o Estado introduz a característica de exclusão pelo uso da água, caracterizando-a como um bem coletivo. Portanto, a característica de bens públicos à qual a água de irrigação em Cristalina está sujeita é a responsável pela

\footnotetext{
De acordo com o que elucida Hardin (1968) em seu artigo 'The tragedy of Commons', o livre acesso ao recurso finito tende a ocasionar uma superexploração deste, dado que os benefícios privados que a utilização proporciona superam os custos da exploração, uma vez que eles são compartilhados dentre todos os setores para os quais o recurso está acessível.

2 Segundo dados do cadastramento dos irrigantes goianos, realizado pela Secretaria de Estado da Agricultura, Pecuária e Irrigação (SEAGRO, 2014), dos 2.544 irrigantes cadastrados, apenas 1.341 possuem outorga para o uso da água.
} 
ineficiência de mercado, e, por consequência, pela alocação ineficiente dos recursos hídricos na região, demandando do poder público a adoção de instrumentos reguladores.

Diferentes ações e instrumentos de política ambiental são utilizados por diversos países em todo o mundo e apresentam variável grau de efetividade quanto aos resultados alcançados, sendo comumente adotados dois tipos de abordagens para regulamentar os problemas ambientais: instrumentos de comando e controle (CEC) e os instrumentos de mercado (IM). A regulamentação do tipo comando e controle consiste, basicamente, em estabelecer um conjunto de normas e procedimentos que delimitam os padrões aos quais os agentes econômicos precisam adequar-se sob pena de sanção. Os principais instrumentos de regulação ambiental, nesse tipo de abordagem, são as licenças, o zoneamento e os padrões (MARGULIS, 1996).

Dentre os parâmetros técnicos que regulam esse instrumento de gestão, no caso dos recursos hídricos, a Resolução do Conselho Nacional do Meio Ambiente (Conama) no 357/2005 estabelece um padrão técnico de vazão de segurança, relacionado a uma vazão mínima de referência a ser mantida com base no balanço hídrico e nas limitações do corpo hídrico receptor da intervenção (CONAMA, 2005). A Resolução no 09/2005, do Conselho Estadual de Recursos Hídricos (GOIÁs, 2005), instituiu o regulamento do sistema de outorga das águas de domínio do estado de Goiás a partir da definição de critérios para outorga, usos, características e prazos de utilização dos recursos hídricos, consoante o disposto na Lei Federal no 9.433, de 1997 (BRASIL, 1997), e na Lei Estadual no 13.123, de 1997 (GOIÁS, 1997).

Assim, por meio desse instrumento, a análise dos pedidos de outorga considera critérios técnicos para estimar a disponibilidade hídrica, averiguando a possibilidade de atender às demandas dos diversos usuários da água, bem como os possíveis impactos das respectivas intervenções autorizadas. Entretanto, instrumentos CEC carecem de acentuada, eficiente e eficaz fiscalização para que atendam aos propósitos definidos, implicando em custos institucionais do processo de fiscalização (THOMAS et al., 2010).

As políticas de gestão ambiental, conduzidas por instrumentos que utilizam a abordagem de mercado, por inserirem incentivo econômico como parâmetro para a mudança de comportamento dos usuários dos recursos, 'forçando-os' a internalizarem, em seus processos produtivos, o preço dos fatores ambientais, caracteriza uma abordagem regulatória mais flexível do que as provenientes dos instrumentos fundamentados em CEC. Esses instrumentos fundamentam-se no Princípio do Poluidor Pagador (PPP), constituindo, segundo Margulis (1996), políticas que obrigam os agentes responsáveis pelas externalidades a arcarem com os custos necessários para que se atinjam níveis de qualidade ambiental desejados pela autoridade pública.

No que tange à aplicabilidade desses instrumentos na gestão pública dos recursos hídricos, a instituição da cobrança pelo uso da água, conforme a Lei no 9.433/1997, seção IV, prevê a aplicação deste instrumento com a finalidade de promover o uso racional da água, com os objetivos de fornecer ao usuário um indicativo econômico de valor da água, incentivar o uso consciente dos recursos hídricos, combatendo a cultura do desperdício e obter recursos financeiros para a recuperação das bacias hidrográficas do país.

Essa cobrança não é um imposto, mas um instrumento de gestão, cujo pagamento é proporcional ao uso do bem público - recursos hídricos - sendo o valor determinado a partir de consenso entre usuários da 
água, sociedade civil e poder público, os quais têm representantes nos Comitês de Bacia Hidrográfica (CBH). Na maioria dos estados brasileiros, a cobrança pelo uso da água está em fase de implantação, especialmente em regiões com comitês de bacia interestaduais, cujos corpos hídricos são de competência da União (ANA, 2016).

No estado de Goiás, a cobrança pelo uso da água foi iniciada na bacia hidrográfica interestadual do Rio Paranaíba em 2017, esta bacia é composta pelos corpos hídricos que abastecem o município de Cristalina. A cobrança foi estabelecida conforme Deliberação no 61, de 10 de março de 2016, que dispõe, em seu caput, "sobre mecanismos e valores de cobrança pelo uso de recursos hídricos de domínio da União".

\section{METODOLOGIA}

O estudo utilizou o método de pesquisa operacional, aplicando um modelo de programação linear por meio da ferramenta Solver, disponível no Microsoft Office Excel. A pesquisa operacional utiliza modelos matemáticos e tem sido utilizada como metodologia em estudos de analisam a otimização de alternativas para uso dos fatores de produção em empreendimentos agrícolas (BORGES JÚNIOR et al., 2008; CARVALHO et al., 2000; DELGADO et al., 2012; FRIZZONE et al., 1994), sobretudo como estratégia de gestão e planejamento das atividades, tendo o objetivo de encontrar um melhor conjunto de alternativas, dadas as restrições impostas pelo ambiente, as quais geralmente consideram as relações entre a atividade econômica e os recursos naturais. Dessa forma, a pesquisa operacional visa simular a realidade por meio de um conjunto de variáveis que descrevem a dinâmica do sistema e que compõem uma função objetivo com suas distintas restrições (ACKOFF, 1979). A solução adequada será efetivamente encontrada mediante a melhor combinação dos dados das variáveis que comporão as bases para a definição do modelo.

Tabela 1: Custo da água por ciclo de produção de cada cultura.

\begin{tabular}{|c|c|c|c|c|}
\hline \multirow{3}{*}{ Culturas } & \multicolumn{4}{|c|}{ Cenário (valor unitário da cobrança) } \\
\hline & 10 e 2 ano $\left(0,015 / \mathrm{m}^{3}\right)$ & 3o ano $\left(0,020 / \mathrm{m}^{3}\right)$ & 4o ano $\left(0,022 / \mathrm{m}^{3}\right)$ & 5o ano $\left(0,025 / \mathrm{m}^{3}\right)$ \\
\hline & \multicolumn{4}{|l|}{ Custo (R\$) } \\
\hline Alho & 101,97 & 135,96 & 149,55 & 169,95 \\
\hline Batata & 116,64 & 155,52 & 171,07 & 194,40 \\
\hline Cebola & 106,75 & 142,34 & 156,57 & 177,92 \\
\hline Feijão (3a safra) & 95,31 & 127,08 & 139,78 & 158,85 \\
\hline Milho doce & 100,60 & 134,14 & 147,55 & 167,67 \\
\hline Milho semente & 132,37 & 176,50 & 194,15 & 220,62 \\
\hline Tomate industrial & 90,00 & 120,00 & 132,00 & 150,00 \\
\hline Trigo & 121,78 & 162,38 & 178,61 & 202,97 \\
\hline
\end{tabular}

Fonte: CBH Paranaíba (2016) e ANA (2016).

Utilizando a pesquisa operacional, a partir da definição de uma função objetivo de maximização de Receita total proveniente do conjunto de possibilidades de uso do solo pelas culturas irrigadas no município de Cristalina, foram comparados os diferentes cenários, os quais representam os cinco próximos anos, com elevação progressiva dos valores a serem cobrado por unidade de captação do recurso hídrico, em relação ao cenário atual, no qual a água é um fator de produção sem custo para o produtor. A tabela 1 apresenta os custos unitários de água para cada cultura, segundo sua demanda hídrica outorgada, para cada cenário. A demanda hídrica foi obtida do manual de outorga (SEMARH, 2012), o qual concede um total de água 
disponível, segundo a máxima demanda de cada cultura, calculada a partir de parâmetros técnicos definidos conforme exigência das culturas. Algebricamente, pretendeu-se encontrar a solução ótima para a equação:

$$
\operatorname{MaxZ}=\sum_{\mathrm{i}=1}^{\mathrm{N}}(\mathrm{Ri}-\mathrm{CAxITNi}) \mathrm{Xi} \text { (eq.1) }
$$

Dadas as restrições:

$$
\begin{gathered}
\sum_{\mathrm{i}=1}^{\mathrm{N}} \text { INixXi } \leq \mathrm{W} \text { (eq.2) } \\
\sum^{\mathrm{N}_{\mathrm{i}=1} \mathrm{Xi} \leq \mathrm{U}(\text { eq. } 3)}
\end{gathered}
$$

Onde:

$\mathrm{Z}=$ Receita Total $(\mathrm{R} \$)$ - Receita total das culturas irrigadas no município de Cristalina GO $\mathrm{i}$ = cultura irrigada, sendo: 1-Alho; 2- Batata-inglesa; 3- Cebola; 4- Feijão; 5- Milho doce; 6-Milho semente; 7-Tomate; 8-Trigo $\mathrm{R}=$ Receita Unitária $(\mathrm{R} \$ \mathrm{ha})$ - Receita por cultura e por unidade de área $C A=$ Custo unitário da água $\left(R \$ / \mathrm{m}^{3}\right)$ IN = Irrigação necessária por cultura por unidade de área $\left(\mathrm{m}^{3} / \mathrm{ha}\right)$ $\mathrm{X}=$ área total irrigada por cultura (ha) W= Consumo hídrico total pela irrigação em $2015\left(370.516 .740 \mathrm{~m}^{3}\right)$ $\mathrm{U}=$ área total irrigada em 2015 (50.500 ha)

Portanto, a partir do resultado que maximiza a equação (eq.1) foi possível identificar um padrão de máxima eficiência econômica de alocação dos fatores terra e recursos hídricos, dadas as restrições de disponibilidade total de água para irrigação na região (eq.2) e da quantidade de terras atualmente disponíveis (eq.3), tal padrão foi constituído pela combinação ótima de culturas que minimizem o consumo de água e maximizem a receita total na região.

A simulação dos cenários permitiu analisar a efetividade da política pública de cobrança pelo uso da água na gestão dos recursos hídricos e na socioeconomia da região, uma vez que mudanças na configuração agrícola implicam em alterações em todo o sistema de marcado que utilizam essas culturas como bens de consumo direto ou intermediário. Na busca por uma explicação significativa para a dinâmica de uso de solo no sistema, que pudesse subsidiar a determinação de restrições para retração e expansão das culturas irrigadas, conferindo maior representatividade ao modelo, utilizou-se de um modelo diferencial-estrutural (HADDAD et al., 1989), por meio do shift share (PIMENTEL, 1998; YOKOYAMA et al., 1989).

O método shift-share consiste, basicamente, na descrição do crescimento econômico de uma região nos termos de sua estrutura produtiva. O método é composto por um conjunto de identidades - com quaisquer hipóteses de causalidade - que procuram identificar e desagregar componentes de tal crescimento, numa análise descritiva da estrutura produtiva.

Tendo como objetivo a representação de condições mercadológicas mais recentes e um recorte temporal significativo adotou-se, para fins da análise da dinâmica de uso do solo, o período de 2006 a 2015. A tabela 2 apresenta os limites de oscilação mínima (média menos desvio padrão) e máxima (média mais desvio padrão) resultantes da análise.

Tabela 2: Limites mínimo e máximo de oscilação de área (ha) adotados como restrições no modelo de uso do solo no município de Cristalina.

\begin{tabular}{lllll}
\hline Culturas & Média & Desvio padrão & Mínimo & Máximo \\
\hline Alho & 1549 & 488,54 & 1060,45 & 2037,54 \\
\hline Batata-inglesa & 4299 & 1104,64 & 3194,35 & 5403,64 \\
\hline Cebola & 1170 & 681,58 & 488,41 & 1851,58 \\
\hline Feijão & 13850 & 3697,22 & 10152,78 & 17547,22 \\
\hline
\end{tabular}




\begin{tabular}{lllll}
\hline Milho doce & 6112,1 & 3035,40 & 3076,69 & 9147,50 \\
\hline Milho & 6112,1 & 3035,40 & 3076,69 & 9147,50 \\
\hline Tomate & 3084,5 & 1058,40 & 2026,09 & \\
\hline Trigo & 7611,9 & 3761,17 & 3850,72 & 11373,08 \\
\hline Área total & & $\mathbf{5 0 . 5 0 0}$ & \\
\hline
\end{tabular}

Para calcular a receita unitária das diferentes culturas (Tabela 3), utilizou-se dos dados de área, produção e valor da produção agrícola municipal (IBGE, 2010), os quais foram tratados para obtenção de valores médios do período analisado (2006 a 2015), retirando, assim, o efeito das oscilações de preço, inflação e produtividade. Para a cultura de milho semente foi utilizada a base de preços BM\&F BOVESPA menos $15 \%$ do valor, uma vez que esta é a referência adotada no pagamento ao produtor, conforme parâmetros contratuais informados pelas produtoras de semente de milho. As informações de preço de venda e produtividade do milho doce foram fornecidas pelo Sindicato Rural de Cristalina e confirmadas pela Associação dos Irrigantes do Estado de Goiás (Irrigo).

Tabela 3: Preço, produtividade e receita unitária- média do período 2006 a 2015 - para as culturas irrigadas em Cristalina/GO.

\begin{tabular}{llll}
\hline Culturas & $\begin{array}{l}\text { Preço de venda } \\
\text { (R\$/kg) }\end{array}$ & $\begin{array}{l}\text { Produtividade } \\
\text { (kg/ha) }\end{array}$ & $\begin{array}{l}\text { Receita unitária } \\
\text { (R\$/ha) }\end{array}$ \\
\hline Alho & 4,82 & $13.205,00$ & $63.689,13$ \\
\hline Batata-inglesa & 0,81 & $38.200,00$ & $31.043,68$ \\
\hline Cebola & 1,15 & $53.778,00$ & $62.151,30$ \\
\hline Feijão (em grão) & 2,30 & $2.322,00$ & $5.363,10$ \\
\hline Milho doce & 0,5 & $15.000,00$ & $7.500,00$ \\
\hline Milho semente & 0,46 & $5.854,00$ & $2.736,75$ \\
\hline Tomate & 0,38 & $85.807,00$ & $33.228,78$ \\
\hline Trigo (em grão) & 0,77 & $4.818,00$ & $3.749,35$ \\
\hline
\end{tabular}

Fontes: IBGE (2010); Sindicato Rural de Cristalina e Irrigo.

\section{RESULTADOS E DISCUSSÃO}

\section{Resultados da instituição da cobrança pelo uso da água como instrumento público de gestão}

A função objetivo - representa o modelo de planejamento de produção que maximiza a receita total do município, otimizando os fatores de produção: área total cultivada, limites de oscilação de áreas para cada cultura e limite de disponibilidade hídrica. Uma vez concebido o modelo, seguem-se os resultados e a discussão dos cenários resultantes. A Tabela 4 apresenta o cenário de referência, que representa o atual uso dos fatores de produção terra e água. Os coeficientes das variáveis correspondem à receita unitária de cada cultura, sem a cobrança pelo uso da água, e a área ocupada respectivamente. Para esse cenário de referência,

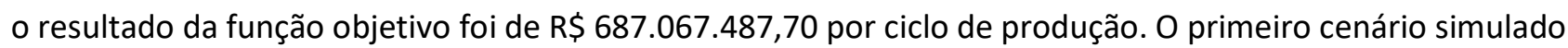
otimiza o cenário de referência (tabela 4), considerando a inexistência da cobrança pelo uso do recurso hídrico, dessa forma não há alteração no coeficiente receita unitária $(R)$ para as culturas irrigadas.

Tabela 4: Cenário de referência para otimização do uso do solo no município de Cristalina/GO.

\begin{tabular}{|c|c|c|c|c|c|c|c|c|}
\hline Culturas (i) & 1 & 2 & 3 & 4 & 5 & 6 & 7 & 8 \\
\hline Receita unitária (R) & 63.689 & 31.043 & 62.151 & 5.363 & 7.500 & 2.736 & 33.228 & 3.749 \\
\hline Área (X) & 1.800 & 4.000 & 2.200 & 10.000 & 12.000 & 12.000 & 3.500 & 5.000 \\
\hline Receita Total (Z) & & & \multicolumn{3}{|c|}{$687.067 .487,70$} & & & \\
\hline
\end{tabular}


A maximização da receita total (Z) (Tabela 5) para o cenário sem cobrança pelo recurso hídrico evidencia que, em condições de otimização, dadas as restrições impostas, o conjunto de culturas e suas respectivas contribuições em termos de área e receita unitária alcançariam uma receita total de $\mathrm{R} \$$ 748.737.569,00 valor esse apenas 8,2\% superior ao encontrado em condições de referência. Isso evidencia que o modelo formulado (referência) representa, significativamente, a trajetória de maximização dos lucros dos empreendedores rurais da região ao longo do período analisado, sugerindo ainda que o sistema se encontra em condições de equilíbrio parcial de curto prazo (uma vez que a terra é tida como fator fixo no sistema).

Tabela 5: Resultado da otimização da função objetivo para o cenário sem cobrança pelo recurso hídrico.

\begin{tabular}{|l|l|l|}
\hline Nome & Valor referencial & Valor final \\
\hline Receita total (Z) & $687.067 .487,70$ & $748.737 .569,00$ \\
\hline
\end{tabular}

Esse resultado é de particular importância no contexto de limitação de dados necessários à execução desta pesquisa, uma vez que não foi possível obter, frente à limitação de recursos operacionais à pesquisa, os custos de produção das diferentes culturas que compõem o modelo. Diante disso, adotou-se a premissa de que, em condições de equilíbrio de curto prazo e, consequentemente, de maximização de lucro por parte dos empreendedores, o sistema estaria sob condições de lucro econômico normal e, portanto, a receita total se iguala ao custo total dos empreendimentos. Essa premissa permite inferir o custo do recurso hídrico como elemento promotor de novo equilíbrio de alocação dos fatores de produção (THOMAS et al., 2010), particularmente o fator terra, objeto do presente estudo. A alteração dos valores das variáveis na função objetivo (Z), as quais representam a área agrícola das culturas representadas pelo modelo, foi mais expressiva em seus resultados (Tabela 6).

Tabela 6: Resultado da otimização das variáveis na função objetivo para o cenário sem cobrança pelo uso do recurso hídrico.

\begin{tabular}{|l|l|l|l|}
\hline Culturas & Área referencial(a) & Área otimizada(b) & Variação relativa (\%) (b-a)/b \\
\hline Alho & $1.800,00$ & $2.037,55$ & 13,19 \\
\hline Batata & $4.000,00$ & $5.403,64$ & 35,09 \\
\hline Cebola & $2.200,00$ & $1.851,58$ & $-15,83$ \\
\hline Feijão & $10.000,00$ & $17.547,22$ & 75,47 \\
\hline Milho doce & $12.000,00$ & $9.147,50$ & $-23,77$ \\
\hline Milho semente & $12.000,00$ & $3.076,70$ & $-74,36$ \\
\hline Tomate industrial & $3.500,00$ & $4.142,90$ & 18,36 \\
\hline Trigo & $5.000,00$ & $7.292,91$ & 45,85 \\
\hline
\end{tabular}

Conforme apresentado, o modelo sugere aumento mais acentuado nas áreas de feijão (75,47\%), trigo $(45,85 \%)$ e batata $(35,09)$, respectivamente, com consequente redução das áreas de milho semente $(74,36 \%)$, milho doce $(23,77 \%)$, e cebola $(15,83 \%)$. Importa salientar que esses resultados ocorrem em função das restrições de limite de expansão e contração das áreas dessas respectivas culturas bem como do comportamento médio de preços e produtividade ao longo do período analisado. Diante disso, algumas contradições se manifestam. Para as áreas de milho, que tiveram uma trajetória de expansão no resultado do modelo de uso do solo (shift-share), o modelo de programação linear indica forte retração e esse resultado 
permite levantar a hipótese de que existem outros fatores, diferentes da receita unitária proveniente dessa cultura, que condicionam a alocação do fator terra.

A análise das restrições adotadas no modelo permite concluir que, de maneira geral, o sistema maximizou as áreas de culturas com receita total mais elevada e minimizou as áreas com receita total menos elevada, fato verificável pelo resultado de 'Associação' às restrições de 'Limite máximo' (Tabela 7). A coluna 'Margem de atraso' apresenta a quantidade de valor da restrição que não foi utilizada e, nesse sentido, ao analisar a relação entre os limites mínimos e margens de atraso para as culturas com menor receita unitária (milho semente e trigo) verifica-se que tais culturas foram minimizadas em suas restrições no sistema.

A combinação da associação de toda a restrição de terra com não associação de toda restrição de recurso hídrico indica que o sistema otimiza o uso do recurso hídrico em função do valor obtido de seu consumo pelas culturas. Isso significa que a quantidade restante deste recurso geraria menos receita, caso tivesse sido integralmente utilizada conforme a combinação de uso do solo no modelo de referência (2015), sugerindo ineficiência econômica do uso do recurso hídrico na região.

Tabela 7: Resultado das restrições para otimização do modelo sem cobrança pelo uso do recurso hídrico.

\begin{tabular}{|l|l|l|l|l|}
\hline Cultura - Limites & Restrição Área (ha) & Valor otimizado Área (ha) & Associação & Margem de Atraso \\
\hline Todas & 50.500 & 50.500 & Sim & 0 \\
\hline Alho - mínimo & 1.060 & 2.037 & Não & 977 \\
\hline Alho - máximo & 2.037 & 2.037 & Sim & - \\
\hline Batata -mínimo & 3.194 & 5.403 & Não & 2.209 \\
\hline Batata - máximo & 5.403 & 5.403 & Sim & - \\
\hline Cebola - mínimo & 488 & 1.851 & Não & 1.363 \\
\hline Cebola - máximo & 1.851 & 1.851 & Sim & - \\
\hline Feijão - mínimo & 10.152 & 16.596 & Não & 7.394 \\
\hline Feijão - máximo & 17.547 & 16.596 & Não & - \\
\hline Milho D - mínimo & 3.076 & 9.147 & Não & 6.070 \\
\hline Milho D - máximo & 9.147 & 9.147 & Sim & - \\
\hline Milho S - mínimo & 3.076 & 3.076 & Sim & - \\
\hline Milho S - máximo & 9.147 & 3.076 & Não & 6.070 \\
\hline Tomate - mínimo & 2.026 & 4.142 & Não & 2.116 \\
\hline Tomate - máximo & 4.142 & 4.142 & Sim & - \\
\hline Trigo - mínimo & 3.850 & 3.850 & Sim & 3.442 \\
\hline Trigo - máximo & 11.373 & 3.850 & Não & 4.080 \\
\hline Consumo hídrico & 370.516 .800 & 353.115 .398 & Não & 17.401 .401 \\
\hline
\end{tabular}

O relatório de sensibilidade das restrições (Tabela 8) apresenta o nível de alterações permitido às restrições (permitido aumentar/reduzir) e o correspondente nível de alteração dos resultados alcançados pelo modelo (preço sombra). Importa destacar que tais alterações são sob condições ceteris paribus entre as variáveis do modelo, ou seja, este limite de variação manteria a proporção entre os valores das variáveis independentes para alcançar a solução ótima no modelo.

As alterações (preço sombra) no resultado do modelo (Max Z) só irão se manifestar para as categorias que utilizaram os limites impostos ao modelo. As categorias que apresentam a conotação infn. em ‘Permitido Aumentar/Reduzir' não apresentam preço sombra e os valores apenas indicam o nível de ajuste adotado na restrição para alcançar o resultado otimizado. Conforme pode ser observado, ainda na Tabela 8, o modelo permite aumentar ou reduzir a área total, em 2.143 ha e 3.422 ha, respectivamente, com variação de R\$ 3.749/ha (preço sombra) aumentado/diminuído, mantendo-se a disponibilidade atual de recurso hídrico. 
Este valor indica o custo de oportunidade médio do fator terra no modelo que maximiza a receita total do município.

Tabela 8: Sensibilidade das restrições do modelo de otimização para o cenário sem cobrança pelo recurso hídrico.

\begin{tabular}{|l|l|l|l|l|l|}
\hline Categorias & $\begin{array}{l}\text { Restrição Adotada } \\
\text { (ha) }\end{array}$ & $\begin{array}{l}\text { Restrição Original } \\
\text { (ha) }\end{array}$ & $\begin{array}{l}\text { Permitido } \\
\text { Aumentar (há) }\end{array}$ & $\begin{array}{l}\text { Permitido Reduzir } \\
\text { (ha) }\end{array}$ & $\begin{array}{l}\text { Preço Sombra } \\
\text { (R\$) }\end{array}$ \\
\hline Área total & $\mathbf{5 0 . 5 0 0}$ & $\mathbf{5 0 . 5 0 0}$ & $\mathbf{2 . 1 4 3}$ & $\mathbf{3 . 4 2 2}$ & $\mathbf{3 . 7 4 9}$ \\
\hline Alho mínimo & 2.037 & 1.060 & 977 & infin. & 0 \\
\hline Alho máximo & 2.037 & 2.037 & 3.442 & 977 & 59.939 \\
\hline Batata mínimo & 5.403 & 3.194 & 2.209 & infin. & 0 \\
\hline Batata máximo & 5.403 & 5.403 & 3.422 & 2.209 & 27.294 \\
\hline Cebola mínimo & 1.851 & 488 & 1.363 & infin. & 0 \\
\hline Cebola máximo & 1.851 & 1.851 & 3.442 & 1.363 & 58.401 \\
\hline Feijão mínimo & 17.547 & 10.152 & 7.394 & infin. & 0 \\
\hline Feijão máximo & 17.547 & 17.547 & 3.442 & 4.080 & 1.613 \\
\hline Milho D mínimo & 9.147 & 3.076 & 6.070 & infin. & 0 \\
\hline Milho D máximo & 9.147 & 9.147 & 3.422 & 4.080 & 3.750 \\
\hline Milho S mínimo & 3.076 & 3.076 & 3.442 & 3.076 & 1.012 \\
\hline Milho S máximo & 3.076 & 9.147 & infin. & 6.070 & 0 \\
\hline Tomate mínimo & 4.142 & 2.026 & 2.116 & infin. & 0 \\
\hline Tomate máximo & 4.142 & 4.142 & 3.442 & 2.116 & 29.479 \\
\hline Trigo mínimo & 7.292 & 3.850 & 3.442 & infin. & 0 \\
\hline Trigo máximo & 7.292 & 11.373 & infin. & $4.080,19$ & 0 \\
\hline Consumo hídrico & $\mathbf{3 5 3 . 1 1 5 . 3 9 8}$ & $\mathbf{3 7 0 . 5 1 6 . 8 0 0}$ & infin. & $\mathbf{1 7 . 4 0 1 . 4 0 1}$ & $\mathbf{0}$ \\
\hline
\end{tabular}

Ainda é possível observar que alho, batata, cebola, feijão, milho doce e tomate promoveriam incrementos na receita total do município $(Z)$ da ordem de $R \$ 59.939, R \$ 27.294, R \$ 58.401, R \$ 1.613, R \$$ 3.750 e $R \$ 29.497$, respectivamente, para cada hectare a mais de incremento nos valores de seus limites máximos. Por outro lado, milho semente promoveria um aumento de $\mathrm{R} \$ 1.012$, para cada hectare que tivesse de diminuição no valor do seu limite mínimo, o qual seria cedido para as demais culturas. Outro resultado, particularmente interessante, é o preço sombra do recurso hídrico igualar-se a zero. Este resultado indica, novamente, que quando o sistema otimiza os fatores terra e água em função da receita total, o recurso hídrico não se apresenta como fator escasso.

A análise do relatório de sensibilidade dos coeficientes da equação do modelo (Tabela 9) apresenta o nível de aumento ou redução permitido ao coeficiente, o qual expressa a receita unitária por cultura, de tal forma que não se alteraria a quantidade de área da respectiva variável (cultura) no modelo otimizado. Os

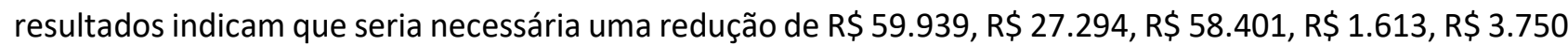
e R\$ 29.497 nas receitas unitárias das culturas de alho, batata, cebola, feijão, milho doce e tomate, respectivamente, bem como um aumento de $\mathrm{R} \$ 1.012$ e $\mathrm{R} \$ 1.613$ na receita unitária do milho semente e trigo, respectivamente, para que a área alocada para essas culturas se alterasse no sistema.

Os demais cenários seriam formulados como função de uma alteração (redução) nas receitas unitárias (coeficientes), proveniente da cobrança pelo uso do recurso hídrico. Entretanto, ao se comparar os resultados da tabela 9, particularmente o campo que indica o nível de redução permitido ao coeficiente sem que haja alteração nas demais variáveis da equação, com os valores de cobrança pelo recurso hídrico instituídos ao longo dos 5 anos (Tabela 1) é possível observar que mesmo os maiores valores a serem deduzidos das receitas unitárias, os quais correspondem ao 5으 ano de cobrança, ainda se distanciam acentuadamente dos limites permitidos de redução indicados anteriormente (Tabela 9). Portanto, esses 
resultados sugerem que os níveis de cobrança instituídos pelo recurso hídrico não teriam impacto efetivo na configuração agrícola do município e, consequentemente na socioeconomia do mesmo.

Tabela 9: Relatório de sensibilidade dos coeficientes da equação do modelo de otimização para o cenário sem cobrança pelo recurso hídrico.

\begin{tabular}{|l|l|l|l|l|l|}
\hline Nome & Área otimizada (ha) & Custo reduzido & Coeficiente & Permitido aumentar & Permitido reduzir \\
\hline Alho & 2.037 & 0 & 63.689 & infn & 59.939 \\
\hline Batata & 5.403 & 0 & 31.043 & infn & 27.294 \\
\hline Cebola & 1.851 & 0 & 62.151 & infn & 58.401 \\
\hline Feijão & 17.547 & 0 & 5.363 & infn & 1.613 \\
\hline Milho D & 9.147 & 0 & 7.500 & infn & 3.750 \\
\hline Milho S & 3.076 & 0 & 2.736 & 1.012 & infn \\
\hline Tomate & 4.142 & 0 & 33.228 & infn & 29.497 \\
\hline Trigo & 7.292 & 0 & 3.749 & 1.613 & 1.012 \\
\hline
\end{tabular}

\section{CONCLUSÕES}

A relevância das discussões quanto à disponibilidade e ao uso da água na irrigação remete à utilização ótima dos recursos hídricos frente ao aumento da concorrência entre usuários. A diminuição gradativa em quantidade e qualidade, dado o aumento da demanda por usuários urbanos, agropecuários e industriais, além da necessidade de manutenção dos diversos ecossistemas, deve ser estímulo para estratégias de gestão que visem alcançar a eficiência no uso do recurso, neste sentido, os sistemas de irrigação deveriam assegurar não somente o retorno financeiro ao irrigante em detrimento do capital investido para o exercício da atividade produtiva, mas, especialmente a minimização de externalidades socioambientais.

Os recursos hídricos, enquanto fator de produção, acarretam em custos mesmo que seu preço não esteja explícito, pois o valor econômico desse recurso encontra-se expresso no gasto com energia para realizar o bombeamento, no investimento para aquisição de equipamento para levar a água do manancial à lavoura e, especialmente, no custo social de oportunidade, por ser um bem público (ALBUQUERQUE, 2004). O uso de sistemas com elevado custo de implantação, deveria ser planejado para produzir culturas que agregassem mais valor, bruto ou líquido, ao recurso utilizado. Já na dimensão social, deveriam estar contabilizados os custos de oportunidade do uso do recurso hídrico (COOK et al., 2006) e, entre estes, a possibilidade de aumento de oferta e, consequente redução de preços pagos pelo consumidor, de culturas de maior valor de mercado. Assim, a gestão de recursos públicos, tais como os recursos hídricos, precisa atender às demandas dos diversos usuários atuais e futuros, com vistas a resguardar a conservação dos ecossistemas, conforme assegurado em lei.

Diante disso, o acesso à água para o exercício de atividades produtivas necessariamente precisa ser concedido por órgão competente, como forma de regular, controlar e planejar o uso dos recursos hídricos. Desse modo, analisar a cobrança pelo uso da água na irrigação por meio da construção de cenários que ilustram o impacto dessa cobrança na receita total do produtor irrigante, permitiu evidenciar efeitos das decisões tomadas pelo poder público.

Os resultados desta pesquisa demonstram que a instituição da cobrança pelo uso da água, nos valores a serem instituídos, não induziriam a mudanças na configuração agrícola produtiva no município de Cristalina, ou seja, os incrementos nos custos de produção não internalizariam efetivamente os custos sociais 
provenientes da utilização do recurso na região, uma vez que não promoveria alterações significativas nas decisões de uso do solo e provavelmente do recurso hídrico. Ao indicar que não ocorreria impacto efetivo na configuração agrícola do município, o modelo permite questionar se a cobrança pelo recurso hídrico estaria cumprindo seu papel como política pública, ou seja, o de estimular as empresas ao contínuo incentivo à procura e a adoção de tecnologias mais eficientes.

Apesar de os resultados sugerirem que não haveria impacto efetivo na configuração agrícola irrigada no município, a cobrança pelo uso do recurso hídrico, nos níveis instituídos, geraria recursos da ordem de R\$ 5.557.752 a $\mathrm{R} \$$ 9.262.920, anualmente, conforme os valores instituídos e o consumo hídrico atual no município. Estes recursos apresentam potencial de transformação efetiva da realidade problematizada, sobretudo tendo em vista a possibilidade de investimentos em soluções chaves aos problemas de escassez hídrica, como o fomento à construção de barragens, estímulos ou subsídios ao aprimoramento tecnológico dos sistemas de irrigação, entre outros.

\section{REFERÊNCIAS}

ACKOFF, R. L.. The future of operational research is past. The Journal of the Operational Research Society, v.30, n.2, p.93104,1979

ALBUQUERQUE, P. E. P.. Aspectos conceituais do uso eficiente da água na agricultura. Painel 03: Eficiência e Otimização do Uso da Água na Agricultura. In: SIMPÓSIO NACIONAL SOBRE O USO DA ÁGUA NA AGRICULTURA. Anais Passo Fundo, 2004.

ANA. Agência Nacional de Águas. Cobrança pelo uso de recursos hídricos: Capacitação em Gestão de Recursos Hídricos. Brasília: SAG, 2014

ANA. Agência Nacional de Águas. Cobrança pelo uso de recursos hídricos. 2016.

BORGES JÚNIOR, J. C. F.; FERREIRA, P. A.; ANDRADE, C. L. T.; HEDDEN-DUNKHORST, B.. Computational modeling for irrigated agriculture planning. Part I: general description and linear programming. Revista Brasileira de Engenharia Agrícola e Ambiental, Campina Grande, v.12, n.1, p.3-11, 2008.

BRASIL. Presidência da República. Lei n. 9.433: Institui a Política Nacional de Recursos Hídricos, cria o Sistema Nacional de Gerenciamento de Recursos Hídricos, regulamenta o inciso XIX do art. 21 da Constituição Federal, e altera o art. 1으 da Lei no 8.001, de 13 de março de 1990, que modificou a Lei no 7.990, de 28 de dezembro de 1989. Brasília: DOU, 1997.

CARVALHO, D. F.; SOARES, A. A.; RIBEIRO, C. A. A. S.; SEDIYAMA, G. C.; PRUSKI, F. F.. Optimization of water use in the Gorutuba irrigation district, Minas Gerais (Brazil) using the linear programming model. Revista Brasileira de Engenharia Agrícola e Ambiental, Campina Grande, v.4, n.2, 2000. DOI: http://dx.doi.org/10.1590/S141543662000000200012

CBH PARANAÍBA. Deliberação no 61: Dispõe sobre mecanismos e valores de cobrança pelo uso de recursos hídricos de domínio da União, propõe as acumulações, derivações, captações e lançamentos de pouca expressão na bacia hidrográfica do rio Paranaíba e dá outras providências. 2016.

CHRISTOFIDIS, D.. Água: gênesis, gênero e sustentabilidade alimentar no Brasil. Brasília, 2006.

CONAMA. Conselho Nacional do Meio Ambiente. Resolução n. 357: Dispõe sobre a classificação dos corpos de água e diretrizes ambientais para o seu enquadramento, bem como estabelece as condições e padrões de lançamento de efluentes, e dá outras providências. 2005.

COOK, S.; GICHUKI, F.; TURRAL, H.. Water productivity: estimation at plot, farm and basin scale. 2006.

DELGADO, A. R. S.; SILVA, W. A.; CARVALHO, D. F.; FORTE, V. L.. Planejamento da agricultura irrigada no norte fluminense, utilizando diferentes técnicas de Programação Matemática. Revista Eletrônica Pesquisa Operacional para o Desenvolvimento, Rio de Janeiro, v.4, n.3, p.249-256, 2012.

FRIZZONE, J. A.. Alocação de água e combinação de atividades pela programação linear em um projeto hidroagrícola no município de Guaíra (SP). Scientia Agrícola, Piracicaba, v.51, n.3, p.524-532, 1994.

FURQUIM, M. G. D.; ABDALA, K. O.. Caracterização preliminar da agricultura irrigada em Cristalina/GO, a estreita relação entre o desenvolvimento sustentável e o crescimento econômico. Revista Irriga, v.1, n.1, 2016.

GOIÁS. Gabinete Civil da Governadoria. Superintendência de Legislação. Lei no 13.123: Estabelece normas de orientação à política estadual de recursos hídricos, bem como ao sistema integrado de gerenciamento de recursos hídricos e dá outras providências. 1997.

GOIÁS. Secretaria do Meio Ambiente e dos Recursos Hídricos. Conselho Estadual de Recursos Hídricos. Resolução no 09: Estabelece o Regulamento do Sistema de outorga das 
águas de domínio do Estado de Goiás e dá outras providências. 2005.

HADDAD, P. R.; FERREIRA, C. M. C.; BOISIER, S.; ANDRADE, T. A.. Economia regional: teorias e métodos de análise. Fortaleza: ETENE-BNE, 1989.

HARDIN, G.. The tragedy of Commons. Science, v.162, n.3859, p.1243-1248, 1968.

HENRIQUES, P. D. D. S.; BRANCO, M. C.; FRAGOSO, R.. Direito de acesso à água: princípios económicos para seu usufruto na agricultura. In: BANCO, M.. Economia do compromisso: Ensaios em Memória de José Sena. Universidade de Évora, 2006. p.29-54.

IBGE. Instituto Brasileiro de Geografia e Estatística. Censo 2010. Rio de Janeiro: IBGE, 2010.

MARGULIS, S.. A regulamentação ambiental: instrumentos e implementação. Rio de Janeiro: TD-437/Ipea, 1996.

MOTA, J. A.. Economia, meio ambiente e sustentabilidade: as limitações do mercado onde o mercado é o limite. Boletim Científico ESMPU, Brasília, v.3, n.12, p.67-87, 2004.

PAULILLO, L. F.. Redes de poder \& territórios produtivos: indústria, citricultura e políticas públicas no Brasil do século XX. São Carlos: RIMA/EDUFSCAR, 2000.

PIMENTEL, C. R.. Evolução recente e tendências da fruticultura nordestina. Revista Econômica do Nordeste, Fortaleza, v.29, n.1, p.11-19, 1998.
RASÇAO, J. P.. A informação estratégica. In: AYALA CALVO, J. C.. Conocimiento, innovación y emprendedores: camino al futuro. La Rioja: Universidad de La Rioja, 2007. p.172.

RIBEIRO, L. C. S.; ROCHA, G. B.. Interdependência produtiva e estratégias de desenvolvimento para o estado da Bahia. Revista Economia Ensaios, Uberlândia, v.27, n.2, p.67-83, 2013.

THOMAS, J. M.; CALLAN, S. J.. Economia ambiental: fundamentos, políticas e aplicações. São Paulo: Cengage Learning, 2010.

SEMARH. Secretaria do Meio Ambiente e dos Recursos Hídricos. Superintendência de Recursos Hídricos. Manual Técnico de Outorga. 2012.

THOMAS, J. M.; CALLAN, S. J.. Economia ambiental: fundamentos, políticas e aplicações. São Paulo: Cengage Learning, 2010.

TORRES, A. T. G.; VIANA, P. C. G.. Reflexões sobre o conceito da água como mercadoria. Dados do cadastramento dos irrigantes fornecidos pela Secretaria de Agricultura, 2005. Não publicado.

YOKOYAMA, L. P.; IGREJA, A. C. M.; NEVES, E. M.. Modelo 'Shift-Share': Uma readaptação metodológica e uma aplicação para o Estado de Goiás. In: CONGRESSO BRASILEIRO DE ECONOMIA E SOCIOLOGIA RURAL, 27. Anais. Piracicaba, 1989, p.63-78.

A CBPC - Companhia Brasileira de Produção Científica (CNPJ: 11.221.422/0001-03) detém os direitos materiais desta publicação. Os direitos referem-se à publicação do trabalho em qualquer parte do mundo, incluindo os direitos às renovações, expansões e disseminações da contribuição, bem como outros direitos subsidiários. Todos os trabalhos publicados eletronicamente poderão posteriormente ser publicados em coletâneas impressas sob coordenação da Sustenere Publishing, da Companhia Brasileira de Produção Científica e seus parceiros autorizados. Os (as) autores (as) preservam os direitos autorais, mas não têm permissão para a publicação da contribuição em outro meio, impresso ou digital, em português ou em tradução. 